\title{
SARS-CoV-2 infection represents a high risk for the elderly: analysis of pathogenesis
}

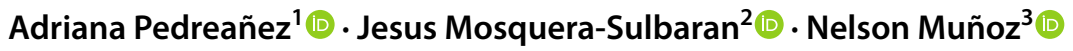 \\ Received: 20 December 2020 / Accepted: 1 February 2021 / Published online: 22 March 2021 \\ (c) The Author(s), under exclusive licence to Springer-Verlag GmbH Austria, part of Springer Nature 2021
}

\begin{abstract}
As people get older, age-related alterations occur that lead to increased susceptibility to disease. In the current COVID19 pandemic, older people are particularly susceptible to a SARS-CoV-2 infection developing into severe disease. The objective of this review was to examine the literature regarding factors that may explain the tendency of this population to develop severe COVID-19. Research articles considered in this review were searched for in EMBASE, PubMed, and Web of Science from December 2019 to December 2020. Citations were screened by two independent reviewers. Studies of the immune system in older individuals found alterations in both the adaptive and innate immune systems. The adaptive system is depressed in its functions, and the innate system is in a pro-inflammatory state that can lead to chronic disease. This proinflammatory state may be related to a severe course of disease in COVID-19. This review shows that the level of evidence supporting an association between immune alterations in the elderly and susceptibly to severe progression of SARS-CoV-2 infection is generally consistent. Preventive measures such as early antiviral treatment are of key importance for prevention of severe progression of COVID19.
\end{abstract}

\section{Introduction}

At the end of 2019, an epidemic of viral pneumonia was reported in the province of Hubei, China [1,2]. Genomic analysis of samples taken from several patients identified a new coronavirus as the responsible pathogen. The genome sequence of this virus was approximately $79 \%$ identical to that of SARS-CoV-1 and matched closely with a bat

Handling Editor: Zhenhai Chen.

Adriana Pedreañez

apedreanez@gmail.com

Jesus Mosquera-Sulbaran

mosquera99ve@yahoo.com

Nelson Muñoz

nemc82@gmail.com

1 Escuela de Bioanálisis, Departamento de Microbiología, Cátedra de Inmunología, Facultad de Medicina, Universidad del Zulia, Maracaibo, Venezuela

2 Instituto de Investigaciones Clínicas "Dr. Américo Negrette". Facultad de Medicina, Universidad del Zulia,, Maracaibo, Venezuela

3 Facultad de Ciencias de la Salud, Universidad Nacional del Chimborazo, Riobamba, Ecuador coronavirus identified previously [2]. The virus, initially named 2019 novel coronavirus (2019-nCoV), was later named SARS-CoV-2 [3]. The World Health Organization (WHO) designated this new coronavirus pneumonia as "COVID-19" (coronavirus 2019 disease), and it spread quickly beyond the borders of China and was declared a pandemic by WHO on March 11, 2020 [4]. Previous studies have shown that during COVID-19, SARS-CoV-2 affects several organs through both the action of the virus on the cell and the reaction of the immune system [5-7]. The severity of the disease is determined by several factors. In this regard, individuals with existing morbidity or advanced age are more susceptible to suffer a severe course of disease [8, 9]. Therefore, the aim of this review was to analyze the link between the immune response of older individuals ("inflammatory aging", "immunosenescence") and the severity of disease caused by SARS-CoV-2 infection.

\section{SARS-CoV-2 infection and pathogenesis}

Regarding the immunopathogenesis of COVID-19, SARSCoV-2 uses the renin-angiotensin system (RAS) to enter, replicate, and produce damage in the cell. An important step in SARS-CoV-2 infection is the binding of the viral S protein to its receptor ACE2, a RAS component [5]. This 
viral infection causes a disease with multiorgan dysfunctions involving the respiratory, renal, cardiovascular, central nervous, and gastrointestinal systems [6].

Structurally, SARS-CoV-2 is a spherical virus covered by a lipid envelope. Its genome, a positive-sense singlestranded RNA molecule, is covered by a nucleocapsid. The virion surface contains proteins that are important for pathogenesis: the $\mathrm{S}$ (spike) protein, which is important for binding to the ACE2 receptor, the M protein, which provides structural support, the E protein, which is necessary for the assembly of the virus particle, and a hemagglutinin esterase $[10,11]$. Before binding to ACE2, the $S$ protein is cleaved by several proteases, including TMPRSS2 (transmembrane serine protease 2), L-cathepsin, and B-cathepsin, but other proteases, such as trypsin, factor $\mathrm{X}$, elastase, and furin may also be involved [12-14]. Binding of the modified S protein to ACE2 facilitates the entry of the virus into the cell and decreases the expression of ACE2 on the cell surface [15, 16]. The ACE2-bound virus is taken into the cell by endocytosis [17]. Initially ACE2 plays a protective role against the harmful effects of angiotensin II (Ang II) (inflammation, fibrosis, oxidative stress, vasoconstriction, cancer) by transforming Ang II into Ang 1-7, which, acting on its receptor Mas, counteracts the effects of Ang II [18]. Internalization of the virus/ACE2 complex results in increased Ang II activity and stimulates expression of ADAM17 (disintegrator and metalloproteinase 17) on the cellular surface. ADAM17 is a protease that cleaves ACE2, decreasing the amount of this molecule on the cell surface [19]. As a result of the increased interaction of Ang II with its receptor AT-1, and through the nuclear translocation of NF-kB [20], Ang II induces the production of pro-inflammatory cytokines, $\mathrm{C}$-reactive protein (CRP), oxidative stress, fibrosis, and vasoconstriction, and it increases the activity of ADAM17 [21], among other harmful effects. In addition, ADAM17 cleaves pro-TNF-alpha in the cell membrane, converting it to its active form, which, when released into the extracellular medium, interacts with its receptor, inducing the production of additional ADAM17 $[22,23]$. As a result of the increased ADAM17 activity on ACE2 and the internalization of the virus/ACE2 complex, there is a drastic reduction of ACE2 on the cell surface and an increase of this molecule in the extracellular space [19]. This process leads to an exaggerated function of Ang II due to a decrease in the conversion of Ang II to Ang 1-7, which leads to inflammatory effects and a drastic increase in the production of cytokines, with consequent deleterious effects [19, 24] (Fig. 1).

SARS-CoV-2 infection and the destruction of cells trigger a local immune response, recruiting macrophages and monocytes that release cytokines, initiating adaptive $\mathrm{T}$ - and

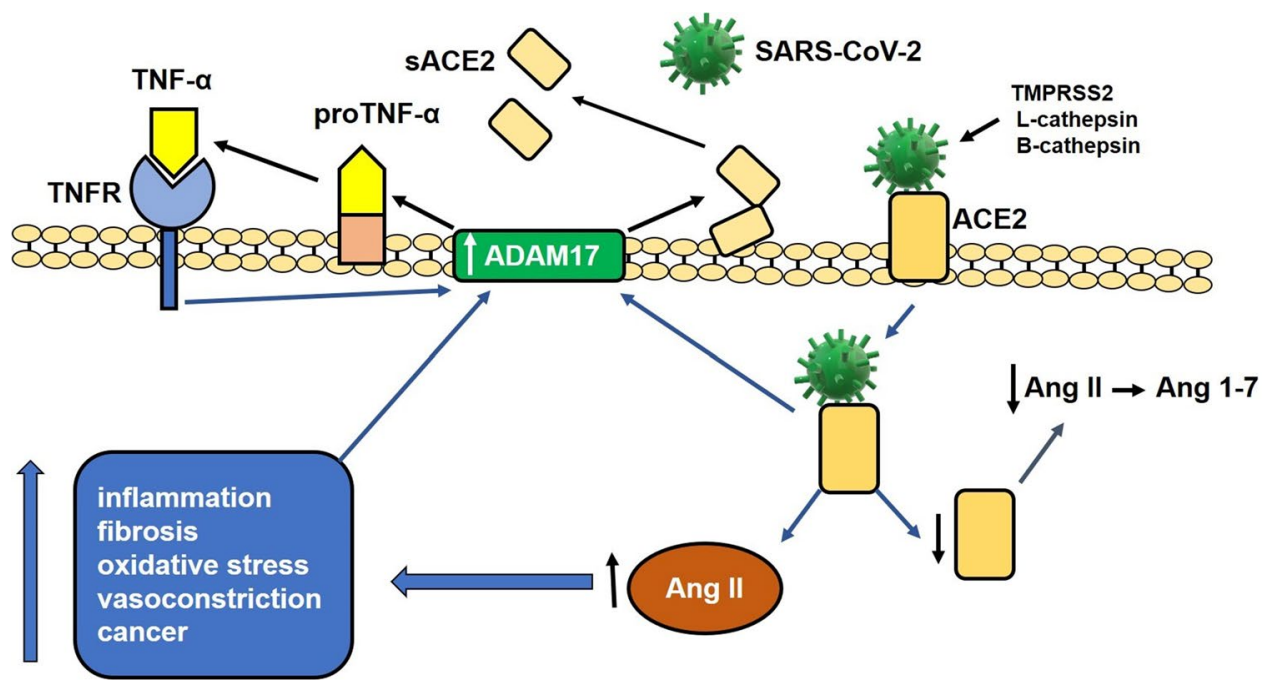

Fig. 1 Involvement of the renin angiotensin system (RAS) in the pathogenesis of SARS-CoV-2 infection. The viral S protein binds to angiotensin I converting enzyme 2 (ACE2) after proteolytic cleavage by TMPRSS2 (serine transmembrane protease 2) and cathepsin L. The binding of the ACE2-cleaved S protein facilitates the entry of the virus into the cell and decreases the expression of ACE2 on the cell surface. The internalization of the virus/ACE2 complex decreases ACE2 levels and increases the activity of angiotensin II (Ang II) and the expression of ADAM17 (disintegrator and metalloproteinase 17) on the cell surface, which, when acting on ACE2, decreases the expression of this molecule on the cell surface. The increased activity of Ang II on the AT1 receptor induces the production of pro-inflammatory cytokines, oxidative stress (ROS), fibrosis, vasoconstriction, production of C-reactive protein (CRP), and increased activity of ADAM17. ADAM17 also acts on pro-TNF-alpha in the membrane, producing an active molecule that interacts with its receptor and induces the production of additional ADAM17. The activity of ADAM17 on ACE2 and the internalization of the virus/ACE2 complex reduce the amount of ACE2 on the cell surface and increase the amount of the soluble form of this molecule (sACE2) in the extracellular space. This process induces an increase in Ang II activity by inhibiting the conversion of Ang II to Ang 1-7, leading to a drastic increase in cytokine production with consequent deleterious effects 
B-cell immune responses. In most cases, this process can resolve the infection; however, in other cases, it results in a dysfunctional immune response, which can cause serious pulmonary, and even systemic, pathology [5-7].

\section{Immune system in the elderly}

With advancing age, changes occur in multiple biological systems [25], including the immune system. Alterations in both the innate and adaptive immune systems have been observed in the elderly $[26,27]$. The effects of age on the innate immune response include a decrease in pathogen recognition, chemotaxis, and phagocytosis, and in adaptive immunity, a decrease in the number of virgin T-lymphocytes and reduced cytotoxicity, as well as in the quality and quantity of antibodies [26]. In general, these immune defects, collectively referred to as "immunosenescence", make the elderly less resistant to infections than young individuals. Immunosenescence occurs due to continual infections or exposure to antigens that affect immunological memory and the pro-inflammatory status (inflammatory aging) [28, 29]. The cytokine-mediated inflammatory process, oxidative stress, and changes in the induction of apoptosis predispose the elderly to chronic disease. In addition, this inflammatory process can alter the adaptive immune system by decreasing the production of virgin $\mathrm{T}$ cells. In this regard, there is a combination of a reduction in virgin $\mathrm{CD}^{+} \mathrm{T}$ cells with clonal expansion of $\mathrm{CD}^{+} \mathrm{T}$ cells and a reduction in $\mathrm{CD}^{+}$ $\mathrm{T}$ cells and $\mathrm{CD} 19^{+} \mathrm{B}$ cells, leading to a weakening of the immune system [30]. At the chromosomal level, one of the main causes of immune depletion is telomere shortening in memory $\mathrm{CD}^{+} \mathrm{T}$ cells, which induces cellular senescence and promotes a state of cell cycle arrest and hyperinflammation that prevents clonal expansion after reinfection [31]. This can also occur in senescent $\mathrm{CD}^{+}{ }^{+} \mathrm{T}$ cells, thus associating inflammation with immunosenescence [32, 33].

Despite the impaired immune response in advanced age, persistence of the pro-inflammatory status results in a constant state of low-grade inflammation, characterized by the production of inflammatory mediators above basal levels [28]. It has been reported that senescent cells have a secretory phenotype associated with senescence and secrete high levels of inflammatory mediators such as IL-6, IL-1 $\beta, \mathrm{TNF} \alpha$, IL-18, IL-8, CCL2, CCL11, growth factors, and proteases [28, 34, 35]. This status during older age may have local and systemic consequences for the individual. Therefore, an increase in the levels of circulating pro-inflammatory cytokines and other factors is an important factor in the development and maintenance of immunosenescence [36, 37] and contributes to chronic diseases of the lung and other organs [28, 38]. In the elderly, innate immune cells are in a sustained state of activation. The increased proinflammatory activity in these cells, especially monocytes/ macrophages, induces a constant state of alert and hyperreactivity. Paradoxically, in old age, while some immune functions are diminished, others are increased [28, 36, 39].

There are multiple theories about the origin and perpetuation of inflammation due to aging. (1) Some reports suggest that increased oxidative stress, DNA damage, and mitochondrial damage induce cellular changes that are detected by cells of the immune system. These alterations, called "damage-associated molecular patterns" (DAMPs), stimulate leukocytes and other cells to secrete pro-inflammatory cytokines [34]. (2) It has been reported that intestinal bacteria may play an important role in inflammation during older age. It has been suggested that changes in intestinal permeability allow bacteria and their products (for example, endotoxins and peptidoglycan) to be transferred to the lymphatic system and finally to the bloodstream, where they can trigger low-intensity systemic inflammation in older individuals. In this regard, the changes in the aging bowel include dysbiosis of the intestinal microbiota in animal models of aging and in elderly humans [40-43] and a decrease in intestinal epithelial cell barrier integrity in both mice and humans [44-46]. (3) The NLRP3 inflammasome could also be involved in the altered inflammatory status in older individuals. During aging, there is a constant increase in the expression and activity of NLRP3 in immune cells, including alveolar macrophages, which, after chronic stimulation, contribute to lung fibrosis [47]. NLRP3 activity is regulated by sirtuin 2 (SIRT2), an $\mathrm{NAD}^{+}$-dependent deacetylase [48], and during aging, levels of $\mathrm{NAD}^{+}$decrease, resulting in reduced sirtuin activity [49]. Accordingly, older mice, especially those deficient in SIRT2, develop a pro-inflammatory state [50] (Fig. 2).

\section{SARS-CoV-2 pathogenesis in the elderly}

SARS-CoV-2 infection has been shown to have distinctive features in elderly adults, who tend to develop more-severe disease than children and young adults. The proportion of older patients among those admitted to the intensive care unit (ICU) is larger than in the group of patients who do not require intensive care [8]. Adults over 65 years old represent $80 \%$ of the hospitalizations and have a 23 times higher risk of death than those under 65 [9]. The reason why the disease is particularly dangerous to older people is not known, but it is clear that age is a risk factor for death by COVID-19 [8, 51]. Zhou and collaborators described the clinical course and risk factors in older adults with COVID-19 in Wuhan, China. Half of the hospitalized patients had a comorbidity: hypertension, $30 \%$; diabetes, $19 \%$; and coronary disease, $8 \%$ [52]. The fatality rate was high among patients with preexisting comorbidities: cardiovascular diseases, $10.5 \%$; diabetes, $7.3 \%$; chronic respiratory disease, $6.3 \%$; hypertension, $6.0 \%$ and cancer, 5.6\% [53]. Diabetic patients infected with 
Fig. 2 Pro-inflammatory status in the elderly. During old age, there is decrease in the activity of the immune system in general. This occurs especially in the adaptive immune system. However, through different mechanisms, a pro-inflammatory status is established in the elderly, known as "inflammatory aging", which causes chronic and systemic inflammation that contributes to diverse diseases

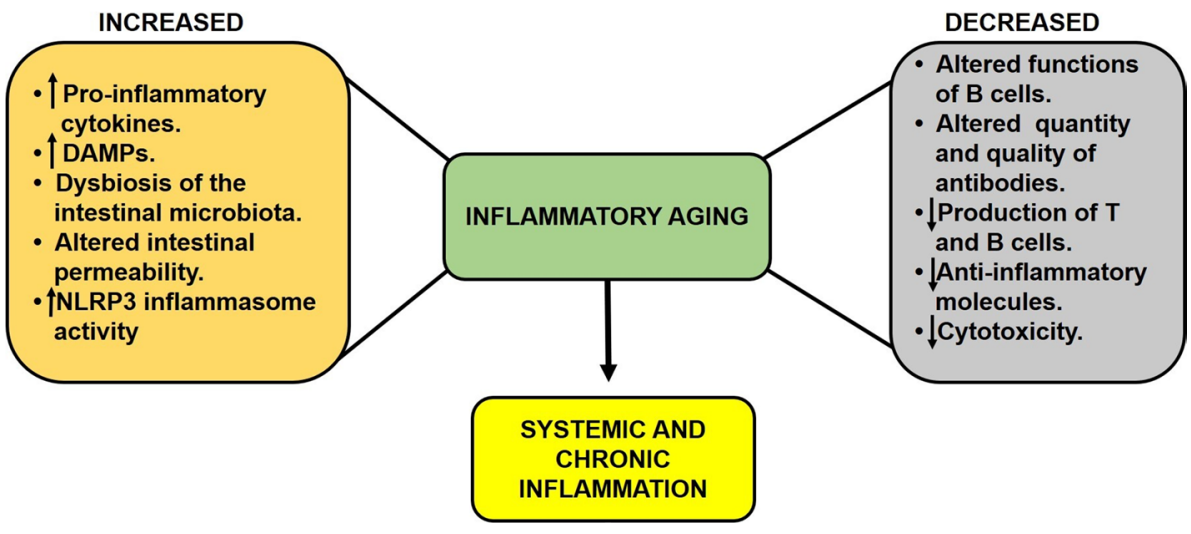

SARS-CoV-2 had higher levels of IL-6, IL-8, and TNF $\alpha$ in their peripheral blood than patients without diabetes [54]. Here, it is important to emphasize that cardiovascular disease, hypertension, and diabetes are diseases related to aging and are associated with a chronic inflammatory state [55]. Older adults are generally more prone to dysregulation of immune responses [56-58], and it has been speculated that immunosenescence, a term used to describe the changes and alterations of the immune system related to age [59], is a key determinant in the evolution of SARS-CoV-2 infection.

When SARS-CoV-2 infects the alveolar cells in older adults, a vigorous and uncontrolled pro-inflammatory immune system occurs. There is also an altered anti-inflammatory response in these patients that correlates with the increased pro-inflammatory activity [60]. Older adults with severe COVID-19 cannot "turn off" their pro-inflammatory response. These patients can quickly enter in a state of shock involving hyperactivation of the immune system and hypercoagulation in small blood vessels [61, 62]. This cascade of rapid and uncontrolled inflammatory signaling typically occurs in the last stages of infection and is known as a "cytokine storm". This immune response exacerbates dyspnea and hypoxia and triggers an intense inflammatory reaction in the lungs, kidneys, heart, liver, and brain [63]. Autopsies of elderly patients who died of COVID-19 have revealed spleen atrophy and necrosis, lymph node necrosis, kidney bleeding, hepatomegaly, and neuronal degeneration in the central nervous system. The number of immune cells also changes during SARS-CoV-2 infection [64, 65]. In fact, lymphopenia with reduced $\mathrm{CD} 4^{+} \mathrm{T}, \mathrm{CD} 8^{+} \mathrm{T}, \mathrm{B}$, and $\mathrm{NK}$ cell counts is a common feature in patients with severe infection [66].

The initial trigger of the cytokine storm is not yet known, but it probably involves detection by the immune system of various viral antigens that are released from dying cells. It is also not clear why some people are particularly prone to a cytokine storm. As mentioned above, aging is associated with elevated systemic levels of pro-inflammatory cytokines, including IL-6, IL-8, TNF- $\alpha$, IL-13, and IFN- $\gamma$, as well as acute-phase proteins. In addition to the cytokine storm, the viral particles of SARS-CoV-2 can also cause multiple organ dysfunction directly due to the viral cytopathic effect $[64,67]$. Several studies have shown that most patients with severe COVID-19 exhibit markedly increased concentrations of pro-inflammatory cytokines in their serum, including IFN- $\alpha$, IFN- $\gamma$, IL-1 $\beta$, IL-6, IL-12, IL-17, IL-18, IL-33, TNF- $\alpha$, G-CSF, GM-CSF, IP10, MCP1, MIP1 $\alpha$, and C-reactive protein (CRP) $[68,69]$, suggesting a combination of the pre-existing pro-inflammatory status observed in older individuals with an additional virus-induced proinflammatory status. Both the increased generation of proinflammatory markers and aging play a fundamental role in the process of cytokine storm development in severe cases of COVID-19 with higher mortality risk [62, 70, 71]. One out of two patients with fatal COVID-19 develops a cytokine storm, and $82 \%$ of these patients are over 60 years old [72]. There are probably many simultaneous storm triggers, but the evidence indicates that inflammation is an important factor [73, 74]. It has been shown that inflammation increases the risk of cytokine storm syndrome in rodents [75], and in humans, age correlates with high circulating levels of proinflammatory cytokines [76, 77]. It is not clear whether the cytokines, the direct effects of viral infection, or a combination of both is the major cause of multiple organ failure in patients with severe COVID-19 [78].

Older age is also associated with a higher viral load in the nasopharynx, suggesting that the virus is able to replicate at a higher rate in these patients, or more likely, that the immune system is not efficient enough to limit infection [79-81]. Differences in the level of expression of the ACE2 molecule between young and old individuals might also contribute to the higher viral loads in older adults; however, there are discrepancies in this regard. Some studies have found higher levels of ACE2 in the lungs of elderly people than in young people [79], but others have found no difference [82].

The NLRP3 inflammasome has been reported to play a possible role in the pathogenesis of COVID-19. The 
activity of NLRP3 is a central factor that could explain the predisposition to cytokine storms [83]. Older people have a constantly elevated level of expression and activity of NLRP3 in immune cells, including alveolar macrophages, which, after chronic stimulation, contribute to lung fibrosis [47]. Therefore, in older people, NLRP3 may be poised for hyperactivation by SARS-CoV-2 antigens. NLRP3 activity is regulated by $\mathrm{NAD}^{+}$-dependent deacetylases [48], and in older individuals, $\mathrm{NAD}^{+}$levels are lower, resulting in hyperactivity of NLRP3 [49]. Overstimulation by SARSCoV-2 could promote the hyperactivation of NLRP3, triggering a cytokine storm in patients with COVID-19 [84] (Fig. 3).

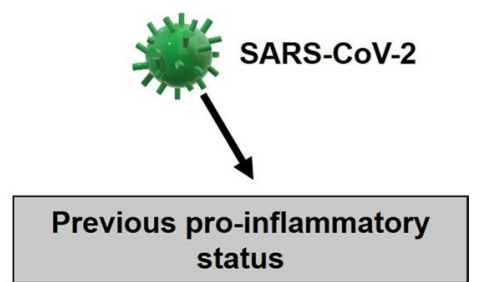

\section{$\uparrow$ Activity of NLRP3}

Higher viral load in the nasopharynx

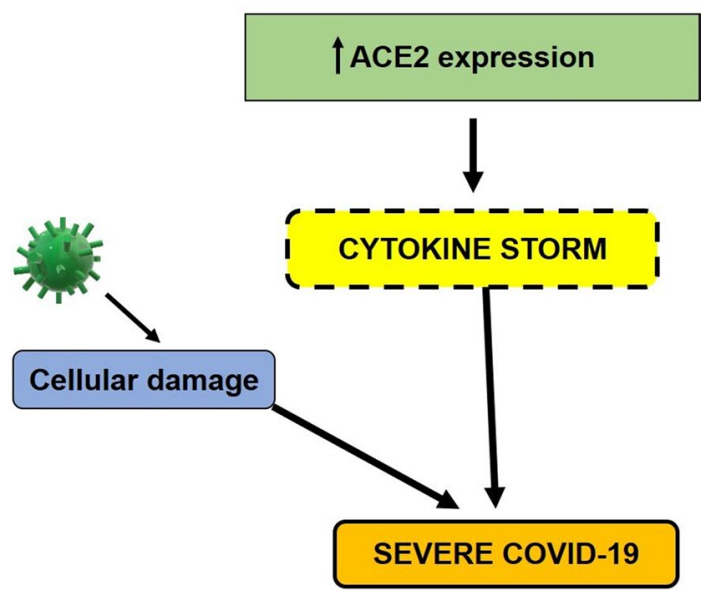

Fig. 3 SARS-CoV-2 pathogenesis in the elderly. The immune system of older individuals tends to remain in a constant pro-inflammatory state that worsens upon infection due to the hyperactivity of angiotensin II induced via the renin angiotensin system. The previous inflammatory status and viral-induced inflammation, together result in an excessive inflammatory immune response that leads to a cytokine storm. In addition, the cellular damage caused by the virus can, in conjunction with the action of cytokines, result in severe disease

\section{Possible role of vitamin D in older people with COVID-19}

Vitamin D is a steroid hormone that is produced endogenously by the effect of ultraviolet radiation on the skin but is also available from exogenous food sources or dietary supplements. It is produced in the skin after exposure to sunlight through a process involving photolysis of cutaneous 7-hydrocholesterol (provitamin D) to pre-vitamin D, followed by isomerization [85]. Vitamin D must be metabolically activated. In this process, the vitamin is first hydroxylated in the liver to $25(\mathrm{OH}) \mathrm{D} 3$ by the action of the enzyme CYP2R1 (a 25-hydroxylase), and then in the kidneys to the hormone metabolite $1,25(\mathrm{OH}) 2 \mathrm{D} 3$ (calcitriol) by the action of the enzyme CYP27B1 ( $\alpha-1$-hydroxylase) [86].

Most of the effects of vitamin D are due to calcitriol, and its mechanism of action involves the regulation of gene expression in specific tissues. This activity is mediated by the vitamin D nuclear receptor (VDR), a DNA-binding protein that interacts directly with regulatory sequences near the target genes. VDR is expressed by several types of immune cells, including monocytes, macrophages, $\mathrm{B}$ and $\mathrm{T}$ lymphocytes, and dendritic cells [87]. In addition, the enzyme $\alpha$-1-hydroxylase is expressed in most immune cells [88] in response to inflammatory conditions [89]. Several studies have addressed the importance of vitamin $\mathrm{D}$ in the regulation of immune responses to infectious processes [90, 91]. Vitamin D exerts immunomodulatory effects, decreasing the expression of proinflammatory genes in immune cells by suppressing the excessive production of ROS, increasing the levels of intracellular glutathione, and suppressing the expression of MAP kinase, NF- $\mathrm{kB}$, and p38 [92]. Vitamin $\mathrm{D}$ can also induce the production of anti-inflammatory cytokines such as IL-10 [93]. Increased expression of VDR and $\alpha$-1-hydroxylase can occur in response to activation of pattern recognition receptors such as Toll-like receptors and NOD-type receptors. This can affect the production of pro-inflammatory cytokines by macrophages, increase the autophagic activity of macrophages, and induce the generation of antimicrobial products, including cathelicidin and $\beta$-defensin [94]. Vitamin D may also suppress differentiation and migration of human dendritic cells and decrease the expression of class II molecules of the main histocompatibility complex in these cells $[95,96]$. Therefore, vitamin D deficiency can result in impaired immune cell function and an imbalance in cytokine production [97, 98].

Older people have a tendency to suffer from vitamin D deficiency, and it has been proposed that this can be attributed to a decreased concentration of 7-dehydrocholesterol in the epidermis, reduced response to ultraviolet light, a lack of exposure to sunlight, or poor dietary intake [99]. On the other hand, it has been shown that there is decreased production of vitamin D in the kidney as kidney function 
Fig. 4 The role of vitamin D in elderly individuals with COVID-19. In general, vitamin D has anti-inflammatory effects. In older people, deficiencies of this vitamin can lead to a pro-inflammatory state that can increase the severity of disease

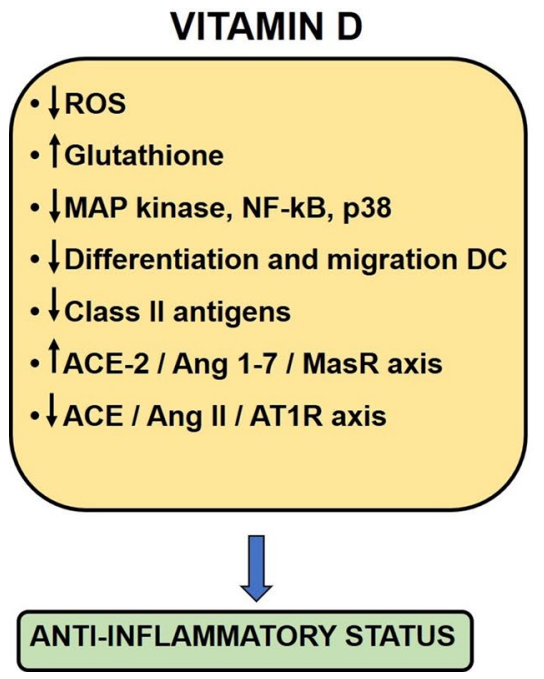

ELDERLY DEFICIT VITAMIN D

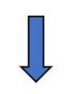

PRO-INFLAMMATORY STATUS

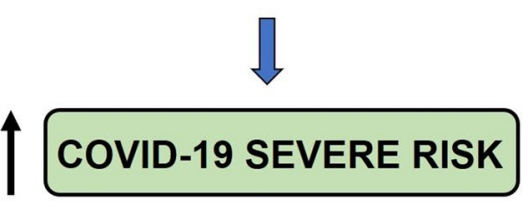

declines with age, accompanied by decreased activity of renal 1- $\alpha$-hydroxylase [100]. Vitamin D deficiency has been associated with several age-related inflammatory diseases, including rheumatoid arthritis, inflammatory bowel disease, multiple sclerosis, cardiovascular disease, hypertension, diabetes mellitus, and cancer [101]. Lack of vitamin D in elderly subjects is associated with the proinflammatory phenotype of immune cells, which is likely to contribute to an increased risk of developing a serious infection in older individuals. In addition, an association between vitamin $\mathrm{D}$ deficiency and the risk of respiratory tract infection in COVID-19 has been described [102, 103]. As discussed above, SARS-CoV-2 binds to host cells via the ACE2 receptor. Previous studies have shown vitamin $D$ to be an endocrine negative modulator of RAS and an inhibitor of renin expression and generation. Vitamin D can activate the ACE2/Ang-1-7/MasR axis and inhibit the ACE/ Ang II/AT1R axis, which increases the expression and concentration of ACE2, MasR, and Ang-1-7 with a potential protective role against acute lung injury and acute respiratory distress syndrome [104]. This protective role would be lacking in individuals with vitamin D deficiency (Fig. 4).

\section{Conclusions}

With increasing age, the immune system seems to remain in a mild sustained inflammatory state (inflammatory aging). This can be induced by phenomena such as oxidative stress, mitochondrial damage, and the generation of DAMPs, which activate the NLRP3 inflammasome. Constant antigenic stimulation, probably due to dysbiosis or increased intestinal mucosa permeability, can also contribute to inflammatory aging. Since regulation by anti-inflammatory molecules is impaired in some older adults, this chronic inflammation becomes harmful. The immune response decreases with aging. Reduced production of $\mathrm{B}$ and $\mathrm{T}$ cells in the bone marrow and the thymus, decreased function of mature lymphocytes in secondary lymphoid tissues, altered function of B cells, and compromised communication between innate and adaptive immunity are age-related changes that together affect the immune system and are called "immunosenescence". Senescent cells secrete high levels of inflammatory mediators. In addition, a lack of vitamin D in elderly individuals is associated with the pro-inflammatory phenotype of immune cells, which is likely to contribute to an increased risk of developing a serious infection. Inflammatory aging and immunosenescence are two phenomena that promote and reinforce each other. Therefore, stimulation by a pathogen such as SARS-CoV-2 can result in an exaggerated immune response in older individuals, favoring the induction of a cytokine storm and death in severe cases of COVID-19. Clinically, SARS-CoV-2 infection may be asymptomatic, produce mild symptoms, or cause severe disease, with elderly patients being at high risk of developing severe disease. Since it is difficult to predict the progression of SARS-CoV-2 infection, it is reasonable to adopt measures to inhibit the virus to prevent severe illness. Antiviral treatment at the onset of SARS-CoV-2 infection may be important for preventing severe disease in elderly patients, patients at high risk, and in the general population to allow a more effective response by the immune system [105].

Acknowledgements This research did not receive any specific grant from funding agencies in the public, commercial, or not-for-profit sector.

Author contributions AP, conceptualization, investigation, data curation, formal analysis, writing the manuscript; JMS, conceptualization, methodology, formal analysis, investigation, writing the manuscript; NM, methodology, investigation. All authors have critically reviewed, discussed, and approved all the content of the manuscript for publication. 


\section{Declarations}

Conflict of interest The authors declare no conflict of interest.

\section{References}

1. Huang C, Wang Y, Li X et al (2020) Clinical features of patients infected with 2019 novel coronavirus in Wuhan China. Lancet 395(10223):497-506. https://doi.org/10.1016/S0140-6736(20) 30183-5

2. Zhou P, Yang X-L, Wang X-G et al (2020) A pneumonia outbreak associated with a new coronavirus of probable bat origin. Nature 579(7798):270-273. https://doi.org/10.1038/s41586-020-2012-7

3. Gorbalenya AE, Baker SC, Baric RS, de Groot RJ, Drosten C, Gulyaeva AA (2020) The species Severe acute respiratory syndrome-related coronavirus: classifying $2019-\mathrm{nCoV}$ and naming it SARS-CoV-2. Nat Microbiol 5(4):536-544. https://doi.org/10. 1038/s41564-020-0695-z

4. WHO Director-General's opening remarks at the media briefing on COVID-19 - 11 March 2020 [Internet]. 2020 https://www. who.int/dg/speeches/detail/who-directorgeneral- s-openingremarks-at-the-media-briefing-on-covid-19---11-march-2020

5. Gheblawi M, Wang K, Viveiros A, Nguyen Q, Zhong JC, Turner AJ (2020) Angiotensin-converting enzyme 2: SARS-CoV-2 receptor and regulator of the renin-angiotensin system: celebrating the 20th anniversary of the discovery of ACE2. Circulation Res 126:1456-1474. https://doi.org/10.1161/CIRCRESAHA. 120.317015

6. Jothimani D, Venugopal R, Abedin MF, Kaliamoorthy I, Rela M (2020) COVID-19 and the liver. J Hepatol 73:1231-1240. https:// doi.org/10.1016/j.jhep.2020.06.006

7. Jiang F, Deng L, Zhang L, Cai Y, Cheung Y, Xia Z (2020) Review of the clinical characteristics of coronavirus disease 2019 (COVID-19). J Gen Intern Med 35(5):1545-1549. https://doi. org/10.1007/s11606-020-05762-w

8. Wang D, Hu B, Hu C et al (2020) Clinical characteristics of 138 hospitalized patients with 2019 novel coronavirus-infected pneumonia in Wuhan China. JAMA 323(11):1061-1069. https:// doi.org/10.1001/jama.2020.1585

9. Chinnadurai R, Ogedengbe O, Agarwal P et al (2020) Older age and frailty are the chief predictors of mortality in COVID-19 patients admitted to an acute medical unit in a secondary care setting- a cohort study. BMC Geriatr 20(1):409. https://doi.org/ 10.1186/s12877-020-01803-5

10. Masters PS (2006) The molecular biology of coronaviruses. Adv Virus Res 66:193-292. https://doi.org/10.1016/S0065-3527(06) 66005-3

11. de Groot RJ (2006) Structure, function, and evolution of the hemagglutinin-esterase proteins of corona and toroviruses. Glycoconj J 23:59-72. https://doi.org/10.1007/s10719-006-5438-8

12. Yan R, Zhang Y, Li Y, Xia L, Guo Y, Zhou Q (2020) Structural basis for the recognition of SARS-CoV-2 by full-length human ACE2. Science 367:1444-1448. https://doi.org/10.1126/science. abb2762

13. Shang J, Ye G, Shi K et al (2020) Structural basis of receptor recognition by SARS-CoV-2. Nature 581:221-224. https://doi. org/10.1038/s41586-020-2179-y

14. Millet JK, Whittaker GR (2015) Host cell proteases: critical determinants of coronavirus tropism and pathogenesis. Virus Res 202:120-134. https://doi.org/10.1016/j.virusres.2014.11.021

15. Li W, Moore MJ, Vasilieva N et al (2003) Angiotensin-converting enzyme 2 is a functional receptor for the SARS coronavirus. Nature 426:450-454. https://doi.org/10.1038/nature02145
16. Walls AC, Park YJ, Tortorici MA, Wall A, McGuire AT, Veesler D (2020) Structure, function, and antigenicity of the SARS-CoV-2 spike glycoprotein. Cell 181:281-292. https:// doi.org/10.1016/j.cell.2020.02.058

17. Wang H, Yang P, Liu K et al (2008) SARS coronavirus entry into host cells through a novel clathrin- and caveolae independent endocytic pathway. Cell Res 18:290-301. https://doi.org/ 10.1038/cr.2008.15

18. Santos RA, Simoes E, Silva AC, Maric C et al (2003) Angiotensin-(1-7) is an endogenous ligand for the $\mathrm{G}$ protein-coupled receptor Mas. Proc Nat Acad Sci U S A 100:8258-8263. https://doi.org/10.1073/pnas.1432869100

19. Patel VB, Clarke N, Wang Z et al (2014) Angiotensin II induced proteolytic cleavage of myocardial ACE2 is mediated by TACE/ADAM-17: a positive feedback mechanism in the RAS. J Mol Cell Cardiol 66:167-176. https://doi.org/10. 1016/j.yjmcc.2013.11.017

20. Kim JM, Heo HS, Ha YM et al (2012) Mechanism of Ang II involvement in activation of NF- $\kappa \mathrm{B}$ through phosphorylation of p65 during aging. Age (Dordr) 34:11-25. https://doi.org/10. 1007/s11357-011-9207-7

21. Scott AJ, O'Dea KP, O'Callaghan D et al (2011) Reactive oxygen species and p38 mitogen-activated protein kinase mediate tumor necrosis factor $\alpha$-converting enzyme (TACE/ADAM17) activation in primary human monocytes. J Biol Chem 286:35466-35476. https://doi.org/10.1074/jbc.m111.277434

22. Black RA, Rauch CT, Kozlosky CJ et al (1997) A metalloproteinase disintegrin that releases tumour-necrosis factor-alpha from cells. Nature 385:729-733. https://doi.org/10.1038/38572 $9 \mathrm{a} 0$

23. Moss ML, Jin SL, Milla ME et al (1997) Cloning of a disintegrin metalloproteinase that processes precursor tumour-necrosis factor-alpha. Nature 385:733-736. https://doi.org/10.1038/38573 $3 \mathrm{a} 0$

24. Xu J, Sriramula S, Xia H et al (2017) Clinical relevance and role of neuronal AT1 receptors in ADAM17-mediated ACE2 shedding in neurogenic hypertension. Cir Res 121:43-55. https://doi. org/10.1161/CIRCRESAHA.116.310509

25. López-Otín C, Blasco MA, Partridge L, Serrano M, Kroemer G (2013) The hallmarks of aging. Cell 153(6):1194-1217. https:// doi.org/10.1016/j.cell.2013.05.039

26. Frasca D, Blomberg BB (2016) Inflammaging decreases adaptive and innate immune responses in mice and humans. Biogerontology 17(1):7-19. https://doi.org/10.1007/s10522-015-9578-8

27. Shaw AC, Goldstein DR, Montgomery RR (2013) Age-dependent dysregulation of innate immunity. Nature Rev Immunol 13(12):875-887. https://doi.org/10.1038/nri3547

28. Franceschi C, Campisi J (2014) Chronic inflammation (Inflammaging) and its potential contribution to age- associated diseases. J Gerontol 69(1):S4-9. https://doi.org/10.1093/gerona/glu057

29. Cevenini E, Monti D, Franceschi C (2013) Inflamm-ageing. Curr Opin Clin Nutr Metab Care 16:14-20. https://doi.org/10.1097/ MCO.0b013e32835ada13

30. Ventura MT, Casciaro M, Gangemi S, Buquicchio R (2017) Immunosenescence in aging: between immune cells depletion and cytokines up-regulation. Clin Mol Allergy 15:21. https://doi. org/10.1186/s12948-017-0077-0

31. Bellon M, Nicot C (2017) Telomere dynamics in immune senescence and exhaustion triggered by chronic viral infection Viruses 9(10): 289. http://www.mdpi.com/1999-4915/9/10/289.

32. Fukushima Y, Minato N, Hattori M (2018) The impact of senescence-associated $\mathrm{T}$ cells on immunosenescence and age-related disorders. Inflamm Regen 38(1):24. https://doi.org/10.1186/ s41232-018-0082-9

33. Callender LA, Carroll EC, Beal RWJ et al (2018) Human CD8+ EMRA T cells display a senescence-associated secretory 
phenotype regulated by p38 MAPK. Aging Cell 17(1):e12675. https://doi.org/10.1111/acel.12675

34. Franceschi C, Garagnani P, Parini P, Giuliani C, Santoro A (2018) Inflammaging: a new immune-metabolic viewpoint for age related diseases. Nature Rev Endocrinol 14(10):576-590. https://doi.org/10.1038/s41574-018-0059-4

35. Schmeer C, Kretz A, Wengerodt D, Stojiljkovic M, Witte OW (2019) Dissecting aging and senescence-current concepts and open lessons. Cells 8(11): 1446. https://www.mdpi.com/20734409/8/11/1446.

36. Franceschi C, Bonafè M, Valensin S et al (2020) Inflamm-aging: An evolutionary perspective on immunosenescence. Ann New York Acad Sci 908(1):244-254. https://doi.org/10.1111/j.1749-. 2000.tb06651.x

37. Solana R, Tarazona R, Gayoso I, Lesur O, Dupuis G, Fulop T (2012) Innate immunosenescence: Effect of aging on cells and receptors of the innate immune system in humans. Semin Immunol 24(5): 331-341. http://www.sciencedirect.com/science/artic le/pii/S1044532312000474.

38. Hearps AC, Martin GE, Angelovich TA et al (2012) Aging is associated with chronic innate immune activation and dysregulation of monocyte phenotype and function. Aging Cell 11(5):867875. https://doi.org/10.1111/j.1474-9726.2012.00851.x

39. Fulop T, Dupuis G, Baehl S et al (2016) From inflamm-aging to immune-paralysis: a slippery slope during aging for immuneadaptation. Biogerontology 17(1):147-157. https://doi.org/10. 1007/s10522-015-9615-7

40. Kim K-A, Jeong J-J, Yoo S-Y, Kim D-H (2016) Gut microbiota lipopolysaccharide accelerates inflamm-aging in mice. BMC Microbiol 16(1):9. https://doi.org/10.1186/s12866-016-0625-7

41. Claesson MJ, Cusack S, O’Sullivan O et al. (2011) Composition, variability, and temporal stability of the intestinal microbiota of the elderly. Proc Nat Acad Sci 108(1): 4586-4591. http://www. pnas.org/content/108/Supplement_1/4586.abs tract

42. Claesson MJ, Jeffery IB, Conde S et al (2012) Gut microbiota composition correlates with diet and health in the elderly. Nature 488(7410): 1781-1784. https://doi.org/10.1038/nature11319

43. Langille MGI, Meehan CJ, Koenig JE et al (2014) Microbial shifts in the aging mouse gut. Microbiomed 2(1):50. https://doi. org/10.1186/s40168-014-0050-9

44. Mabbott NA, Kobayashi A, Sehgal A, Bradford BM, Pattison M, Donaldson DS (2015) Aging and the mucosal immune system in the intestine. Biogerontol 16(2):133-145. https://doi.org/10. 1007/s10522-014-9498-z

45. Mabbott NA (2015) ¿A breakdown in communication? Understanding the effects of aging on the human small intestine epithelium. Clin Sci 129(7):529-531. https://doi.org/10.1042/CS201 50364

46. Valentini L, Ramminger S, Haas V et al (2014) Small intestinal permeability in older adults. Physiol Rep 2(4): e00281. https:// doi.org/10.14814/phy2.281.

47. Stout-Delgado HW, Cho SJ, Chu SG et al (2016) Age-Dependent susceptibility to pulmonary fibrosis is associated with NLRP3 inflammasome activation. Am J Resp Cell Mol Biol 55(2):252263. https://doi.org/10.1165/rcmb.2015-0222OC

48. He M, Chiang H-H, Luo H et al (2020) An acetylation switch of the NLRP3 inflammasome regulates aging-associated chronic inflammation and insulin resistance. Cell Metab 31(3):580-591. https://doi.org/10.1016/j.cmet.2020.01.009

49. Massudi H, Grant R, Braidy N, Guest J, Farnsworth B, Guillemin GJ (2012) Age-associated changes in oxidative stress and NAD+ metabolism in human tissue. PLoS ONE 7(7):e42357. https://doi. org/10.1371/journal.pone.0042357

50. Lantier L, Williams AS, Hughey CC et al (2018) SIRT2 knockout exacerbates insulin resistance in high fat-fed mice. PLoS ONE 13(12):e0208634. https://doi.org/10.1371/journal.pone.0208634
51. Santesmasses D, Castro JP, Zenin AA et al (2020) COVID-19 is an emergent disease of aging. Aging Cell 19:e13230. https:// doi.org/10.1111/acel.13230

52. Zhou F, Yu T, Du R et al (2020) Clinical course and risk factors for mortality of adult inpatients with COVID-19 in Wuhan, China: a retrospective cohort study. Lancet 395(10229):10541062. https://doi.org/10.1016/S0140-6736(20)30566-3

53. Wu Z, McGoogan JM (2020) Characteristics of and important lessons from the coronavirus disease 2019 (COVID-19) outbreak in China: summary of a report of 72314 cases from the Chinese center for disease control and prevention. JAMA 323(13):1239-1242. https://doi.org/10.1001/jama.2020.2648

54. Yan Y, Yang Y, Wang F et al (2020) Clinical characteristics and outcomes of patients with severe covid-19 with diabetes. BMJ Open Diab Res Care 8(1): e001343. http://drc.bmj.com/ content/8/1/e001343.abstract.

55. Jaul E, Barron J (2017) Age-related diseases and clinical and public health implications for the 85 years old and over population. Front Public Health 5: 335. https://www.frontiersin.org/ article/https://doi.org/10.3389/fpubh.2017.00335.

56. Pinti M, Appay V, Campisi J et al (2016) Aging of the immune system: Focus on inflammation and vaccination. Eur J Immunol 46(10):2286-2301. https://doi.org/10.1002/eji.201546178

57. Ciabattini A, Nardini C, Santoro F, Garagnani P, Francesch C, Medaglini D (2018) Vaccination in the elderly: The challenge of immune changes with aging. Semin Immunol 40:83-94. https://doi.org/10.1016/j.smim.2018.10.010

58. Nikolich-Žugich J (2018) The twilight of immunity: emerging concepts in aging of the immune system. Nature Immunol 19(1):10-19. https://doi.org/10.1038/s41590-017-0006-x

59. Nikolich-Zugich J, Knox KS, Rios CT, Natt B, Bhattacharya D, Fain MJ (2020) SARS-CoV-2 and COVID-19 in older adults: what we may expect regarding pathogenesis, immune responses, and outcomes. GeroScience 42(2):505-514. https:// doi.org/10.1007/s11357-020-00186-0

60. Cao X (2020) COVID-19: immunopathology and its implications for therapy. Nature Rev Immunol 20(5):269-270. https:// doi.org/10.1038/s41577-020-0308-3

61. Diao B, Wang C, Ta, Y et al (2020) Reduction and Functional Exhaustion of T Cells in Patients With Coronavirus Disease 2019 (COVID-19). Front Immunol 11: 827. https://www.frontiersin.org/article/https://doi.org/10.3389/fimmu.2020.00827.

62. Terpos E, Ntanasis-Stathopoulos I, Elalamy I et al (2020) Hematological findings and complications of COVID-19. Am J Hematol 95(7):834-847. https://doi.org/10.1002/ajh.25829

63. Weaver LK, Behrens EM (2017) Weathering the storm: improving therapeutic interventions for cytokine storm syndromes by targeting disease pathogenesis. Curr Treat Opt Rheumatol 3(1):33-48. https://doi.org/10.1007/s40674-017-0059-x

64. Li H, Liu L, Zhang D et al (2020) SARS-CoV-2 and viral sepsis: observations and hypotheses. Lancet 395(10235):15171520. https://doi.org/10.1016/S0140-6736(20)30920-X

65. Park MD (2020) Macrophages: a Trojan horse in COVID19? Nature Rev Immunol 20(6):351. https://doi.org/10.1038/ s41577-020-0317-2

66. Zhang W, Zhao Y, Zhang F et al (2020) The use of anti-inflammatory drugs in the treatment of people with severe coronavirus disease 2019 (COVID-19): The Perspectives of clinical immunologists from China. Clin Immunol 214:108393. http:// www.sciencedirect.com/science/article/pii/S15216616203019 84.

67. Zhu N, Zhang D, Wang W et al (2019) (2020) A novel coronavirus from patients with pneumonia in China. New Engl J Med 382(8):727-733. https://doi.org/10.1056/NEJMoa2001017

68. Schett G, Sticherling M, Neurath MF (2020) COVID-19: risk for cytokine targeting in chronic inflammatory diseases? 
Nature Rev Inmunol 20(5):271-272. https://doi.org/10.1038/ s41577-020-0312-7

69. Tan L, Zhang WQ, D, et al (2020) Lymphopenia predicts disease severity of COVID-19: a descriptive and predictive study. Sign Transd Targ Ther 5(1):33. https://doi.org/10.1038/ s41392-020-0148-4

70. Xia S, Zhang X, Zheng S et al (2016) An update on inflammaging: mechanisms, prevention, and treatment. J Immunol Res 2016:8426874. https://doi.org/10.1155/2016/8426874

71. Koelman L, Pivovarova-Ramich O, Pfeiffer AFH, Grune T, Aleksandrova K (2019) Cytokines for evaluation of chronic inflammatory status in ageing research: reliability and phenotypic characterisation. Immun Age 16(1):11. https://doi.org/10.1186/ s12979-019-0151-1

72. Paranjpe I, Russak A, De Freitas JK et al (2020) Clinical characteristics of hospitalized Covid-19 patients in New York City. medRxiv, 2020.04.19.20062117. http://medrxiv.org/content/ early/2020/04/26/2020.04.19.20062117.abstract.

73. Sanada F, Taniyama Y, Muratsu J et al (2018) Source of chronic inflammation in aging. Front Cardiovasc Med 5: 12. https://www. frontiersin.org/article/https://doi.org/10.3389/fcvm.2018.00012.

74. Buford TW, Carter CS, VanDerPol WJ et al (2018) Composition and richness of the serum microbiome differ by age and link to systemic inflammation. GeroScience 40(3):257-268. https://doi. org/10.1007/s11357-018-0026-y

75. Mirsoian A, Bouchlaka MN, Sckisel GD et al (2014) Adiposity induces lethal cytokine storm after systemic administration of stimulatory immunotherapy regimens in aged mice. J Exp Med 211(12):2373-2383. https://doi.org/10.1084/jem.20140116

76. Krabbe KS, Pedersen M, Bruunsgaard H (2004) Inflammatory mediators in the elderly. Exp Gerontol 39(5):687-699. http:// www.sciencedirect.com/science/article/pii/S0531556504000531.

77. Rea IM, Gibson DS, McGilligan V, McNerlan SE, Alexander HD, Ross OA (2018) Age and age-related diseases: role of inflammation triggers and cytokines. Front Immunol 9: 586. https://www.frontiersin.org/article/https://doi.org/10.3389/ fimmu.2018.00586.

78. Tay MZ, Poh CM, Rénia L, MacAry PA, Ng LFP (2020) The trinity of COVID-19: immunity, inflammation and intervention. Nature Rev Inmunol 20(6):363-374. https://doi.org/10.1038/ s41577-020-0311-8

79. Chen Y, Li L (2020) SARS-CoV-2: virus dynamics and host response. Lancet Infect Dis 20(5):515-516. https://doi.org/10. 1016/S1473-3099(20)30235-8

80. To KK-W, Tsang OT-Y, Leung W-S et al (2020) Temporal profiles of viral load in posterior oropharyngeal saliva samples and serum antibody responses during infection by SARS-CoV-2: an observational cohort study. Lancet Infect Dis 20(5):565-574. https://doi.org/10.1016/S1473-3099(20)30196-1

81. Pan Y, Zhang D, Yang P, Poon LLM, Wang Q (2020) Viral load of SARS-CoV-2 in clinical samples. Lancet Infect Dis 20(4):411-412. https://doi.org/10.1016/S1473-3099(20)30113-4

82. Li M-Y, Li L, Zhang Y, Wang X-S (2020) Expression of the SARS-CoV-2 cell receptor gene ACE2 in a wide variety of human tissues. Infect Dis Poverty 9(1):45. https://doi.org/10. 1186/s40249-020-00662-x

83. Pedreañez A, Mosquera J, Muñoz N (2020) Inflamasoma, piroptosis y su posible relación con la fisiopatología del covid-19. Invest Clin 61(3):283 -293. https://doi.org/10.22209/IC.v61n3 a07.

84. Kouhpayeh S, Shariati L, Boshtam M et al (2020) The Molecular Story of COVID-19; NAD+ Depletion Addresses All Questions in this Infection. https://www.preprints.org/manuscript/202003. 0346/v1\#.

85. DeLuca HF (1998) The vitamin D story: a collaborative effort of basic science and clinical medicine. FASEB J 2(3):224-236
86. Pike JW, Christakos S (2017) Biology and mechanisms of action of the vitamin D hormone. Endocrinol Metab Clin North Am 46(4):815-843. https://doi.org/10.1016/j.ecl.2017.07.001

87. Joshi S, Pantalena LC, Liu XK et al (2011) 1,25-dihydroxyvitamin $\mathrm{D}(3)$ ameliorates Th17 autoimmunity via transcriptional modulation of interleukin-17A. Mol Cell Biol 31(17):36533669. https://doi.org/10.1128/MCB.05020-11

88. Sassi F, Tamone C, D'Amelio P (2018) Vitamin D: Nutrient, Hormone, and Immunomodulator. Nutrients 10(11):1656. https://doi.org/10.3390/nu10111656

89. Gyetko MR, Hsu CH, Wilkinson CC, Patel S, Young E (1993) Monocyte 1 alpha-hydroxylase regulation: induction by inflammatory cytokines and suppression by dexamethasone and uremia toxin. J Leuk Biol 54(1):17-22. https://doi.org/10.1002/ jlb.54.1.17

90. Gombart AF, Pierre A, Maggini S (2020) A review of micronutrients and the immune system-working in harmony to reduce the risk of infection. Nutrients 12(1):236. https://doi.org/10. 3390/nu 12010236

91. Lang PO, Aspinal R (2017) Vitamin D status and the host resistance to infections: what it is currently (Not) understood. Clin Ther 39(5):930-945. https://doi.org/10.1016/j.clinthera. 2017.04.004

92. Kim DH, Meza CA, Clarke H, Kim JS, Hickner RC (2020) Vitamin D and endothelial function. Nutrients 12(2):575. https://doi.org/10.3390/nu12020575

93. Hoe E, Nathanielsz J, Toh ZQ et al (2016) Anti-Inflammatory effects of vitamin D on human immune cells in the context of bacterial infection. Nutrients 8(12):806. https://doi.org/10. 3390/nu8120806

94. Wöbke TK, Sorg BL, Steinhilber D (2014) Vitamin D in inflammatory diseases. Front Physiol 5:244. https://doi.org/ 10.3389/fphys.2014.00244

95. Liu CY, Zhang ZH, Yang HF, Xu H, Cheng FF, Xu JZ (2016) Effect of vitamin D3 on maturation and antigen-presenting function of dendritic cells treated with Mycobacterium tuberculosis. Asian Pac J Trop Med 9(1):54-57. https://doi.org/10. 1016/j.apjtm.2015.12.011

96. Barragan M, Good M, Kolls JK (2015) Regulation of dendritic cell function by vitamin D. Nutrients 7(9):8127-8151. https:// doi.org/10.3390/nu7095383

97. Peterson CA, Heffernan ME (2008) Serum tumor necrosis factor-alpha concentrations are negatively correlated with serum $25(\mathrm{OH}) \mathrm{D}$ concentrations in healthy women. J Inflamm (London, England) 5:10. https://doi.org/10.1186/1476-9255-5-10

98. Milovanovic M, Pesic G, Nikolic V et al (2012) Vitamin D deficiency is associated with increased IL-17 and TNF $\alpha$ levels in patients with chronic heart failure. Arq Bras Cardiol 98:259-265. https://doi.org/10.1590/s0066-782x20120050000 19

99. Gallagher JC (2013) Vitamin D and aging. Endocrinol Metab Clin North Am 42:319-332. https://doi.org/10.1016/j.ecl.2013. 02.004

100. Tsai KS, Heath H III, Kumar R, Riggs BL (1984) Impaired vitamin D metabolism with aging in women. Possible role in pathogenesis of senile osteoporosis. J Clin Invest 73:1668-1672. https://doi.org/10.1172/JCI111373

101. Aslam MM, John P, Bhatti A, Jahangir S, Kamboh MI (2019) Vitamin D as a principal factor in mediating rheumatoid arthritis-derived immune response. Biomed Res Int 2019:3494937. https://doi.org/10.1155/2019/3494937

102. Ebadi M, Montano-Loza AJ (2020) Perspective: improving vitamin D status in the management of COVID-19. Eur J Clin Nutr 74(6):856-859. https://doi.org/10.1038/s41430-020-0661-0

103. Honardoost M, Ghavideldarestani M, Khamseh ME (2020) Role of vitamin D in pathogenesis and severity of COVID-19 
infection. Arch Physiol Biochem 30:1-7. https://doi.org/10.1080/ 13813455.2020

104. Malek Mahdavi A (2020) A brief review of interplay between vitamin D and angiotensin-converting enzyme 2: Implications for a potential treatment for COVID-19. Rev Med Virol 30(5):e2119. https://doi.org/10.1002/rmv.2119

105. Mosquera-Sulbaran J, Hernandez-Fonseca H (2021) Tetracycline and viruses: a possible treatment for COVID-19? Arch Virol 166:1-7. https://doi.org/10.1007/s00705-020-04860-8
Publisher's Note Springer Nature remains neutral with regard to jurisdictional claims in published maps and institutional affiliations. 